\title{
DEVELOPING E-LEARNING SYSTEM TO SUPPORT MATH IN THAI EDUCATION Curriculum (Primary LeVEL)
}

\author{
Piya Techateerawat \\ Engineering Faculty, Thammasat University, Thailand
}

\begin{abstract}
E-learning is a common tool to support the education in variety of scenarios. As the education content can be prepared by the group of specialists, but the skilled teachers are limited in remote area. Also, the contents in most curriculum are planned to distribute to limited skilled people. The gap of education can be full-filled with E- learning system. However, the conventional E-learning is high cost system and not appropriated for rural area. Also, opensource system is complicated to implement and configure in dedicated curriculum. This research is proposed the customized design of E-learning system for primary Thai education curriculum. As Thai education curriculum was updated in 2017, school and teacher need to update the plan and methodology accordingly. Our research is based on the actual Thai school in Ratchaburi province by using the Android framework. The system is designed and implemented from actual requirements from teachers and students in grade 3. As a result, the result show student involvement and continue using of system in both school and extra hours. The feedback from actual usage also is evaluated.
\end{abstract}

\section{KEYWORDS}

E-learning, Android, Thai Curriculum.

\section{INTRODUCTION}

Electronic learning (E-learning) is a general system to support the learning process and assist the content delivering to the specified learner. The key features of E-learning are to let learner access contents promptly with less constraints e.g. remote area, limited time, lack of teacher and large number of learners. Since network performance and equipment are easily access currently, a number of learners' request more of E-learning system. Also, learners expect to use E-learning for knowledge sharing and on-demand contents.

This paper shows the customized solution of E-learning system that can be implemented in adaptive content with specified need (2017 Thai education curriculum) The solution also can be applied to other scenarios for other organizations.

\section{E-LEARNING SYSTEM}

E-learning is shown as critical system for content sharing in business, research and academic. Since the market share of E-learning system reached \$2 trillions in 2001, many organizations implement the system for accessible and extra class support $[1,2]$.

David C. Wyld et al. (Eds): SAIM, SIPM, ACSIT, FCST, ICITE - 2020

pp. 15-21, 2020. CS \& IT - CSCP 2020

DOI: $10.5121 /$ csit.2020.100802 
The main benefit of E-learning system is cost effective, flexibility, accessibility and content distribution. As the system are content centralized and using the technology platform for access anywhere-anytime. Then overall, it reduced the cost of staff, operation task and open the opportunity to more people [3]. It also adds more features that can provide online chat, AI enquiry, reminder, online quiz and content suggestions.

In general, large system is approaching with framework [4-5]. As developing time can be reduced significantly by using the built-in library. The security is conformed by the framework library as well as updating regularly with framework update. The important key is maintenance as framework using the standard model following with guidance.

The one of challenge of implementing E-learning is cost that increased 83 percent from 19982003 [6]. This is a struggle for many organizations especially in education system. However, the need of E-learning also pushes to one of the largest share markets [7]. For, specific small organization and limited budget company are difficult to access to the commercialized platform as well as the open source system also required the skilled person to configure and understand that need follow the scheme of open source package.

\section{FRAMEWORK}

Android framework is a structure that prepare for programmer to develop application. Adobe Illustrator and Figma are the of tools to design on UI and character based. SQLite is use for database of quiz and content storage. This assist for both user and backend side to communicate and interact and share contents over the network. Most of Android framework is based on JDK model, this scheme let programmer customize the framework to meet the requirement by using the universal programming language and layout organization that is compatible to designated devices. Also, most of the framework is based on open source, so it can minimize the cost of license and maintenance.

The advantage of using this framework is let the structure more robust and more secure from the prepared package compared to developing from bare bone. In addition, the framework has prepared the libraries and themes for developer to choose and apply. So, implementation can be rapid and more convenience to meet the requirement.

SQLite provides the up-to-date content structure that can add, delete and modify the content of application on the fly. These support the upcoming content update from the education curriculum.

The special request is also to add the gaming features. The project designs the main character model of the game in Adobe Illustrator and lay it on Figma to handle the flexible of mobile device. This game contains many scenes such as Main Scene, Menu Scene, Game Scene etc., and the application also includes the question scene.

The gaming section in layout based on the purpose of core education curriculum in math subject. Also, all the main features can be operated in Android system.

\section{Planning \& Development}

This E-learning system is based on the actual case from Thai School in Ratchaburi province. The group of primary students and teacher in 2018 is based on the research. The development and evaluation are also based on the actual activity that interacts with students. 
The design must be compatible to the new mobile devices (e.g. smart phone and tablets). The contents in each screen should be simplified with one main idea.

The purpose of this E-learning system is to support the actual class and student has sufficient knowledge in using computer technology. The requirement and design of this system is survey from in-class students.

\subsection{Requirement}

- The system must be convenient for in-class student to apply and access.

- Students which do not enrol may apply and register for the interest class.

- Every user can browse the contents in subject.

- The interface should be kids friendly.

- The objective must follow the core curriculum.

- The quiz must the task of activities in the class.

- The flow of application should let the student feel enjoy.

\subsection{Application Design}

This application is focused to the math subject from Thai core curriculum. In primary, 5 topics are the main education topics: 1.) Calculation 2.) Measurement 3.) Weight 4.) Time and 5.) Shape. Our design is to support the main class activities that provide the summary video and quiz. For each topic in curriculum the amount of content is weigh by the teacher plan as follows:

The main page of application is focused on 5 main tasks: 1.) Calculation 2.) Measurement 3.) Weight 4.) Time and 5.) Shape. This page let student to navigate and see the overview of task where the character and symbolic to illustrate grade 3 students easily follow the assigned task from teacher as shown in figure 1. The character in the application is from the brainstorm of student and teacher in the school to get the sketch and forming up by the research team. As a result, the collaboration leads the students the feel involves and willing to join the tasks and activities as shown in figure 2 .

In calculation section, the tasks are addition, subtraction, multiplication and division. Once, the user selects the topics the detail of given topics will be shown. The drill-down UI is provided and given in each section and provided the given content and video which is approved by teacher as shown in figure 3.

In quiz section, the quiz is based on the learning knowledge by pulling up the question from SQLite and arrange by the selected topics. When the user finishes the quiz, simple mark output is given. The quiz allows the user to re-do in the case the gain the understanding as shown in figure 4. 


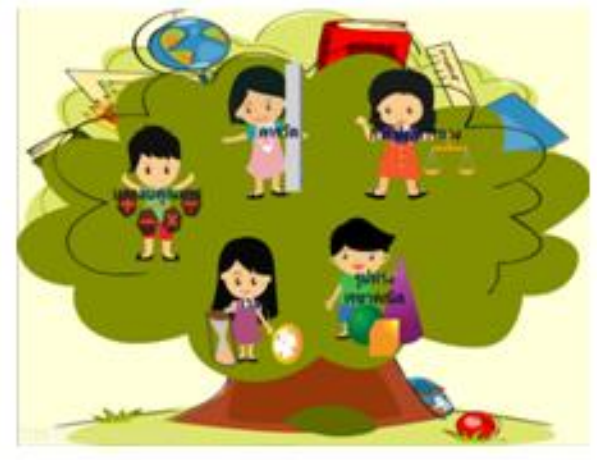

Fig. 1. Main Application Design

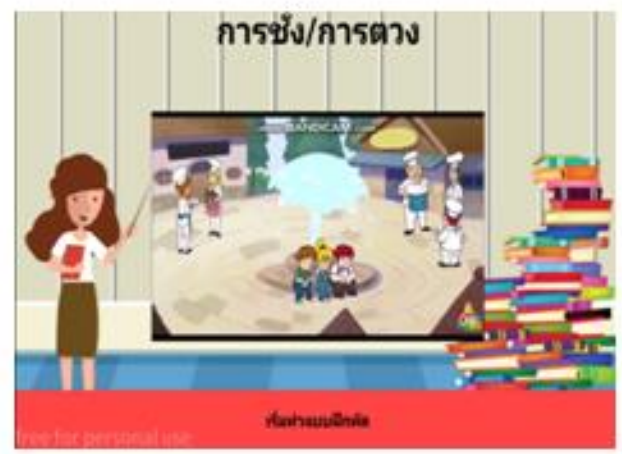

Fig. 3. Video Content

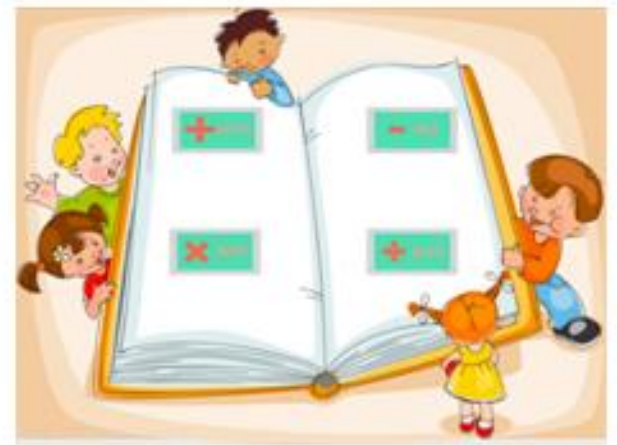

Fig. 2. Sub-Menu: Calculation Section

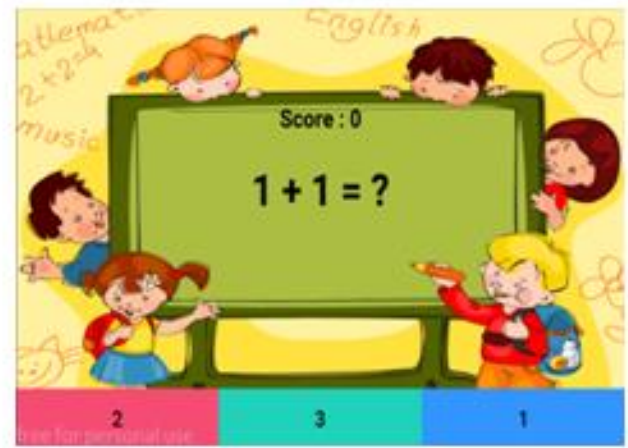

Fig. 4. Quiz Section

To support the flexible in design, background is laid with browser in Android studio. The character is drawn by Adobe Illustrator or equivalent and lay it with Figma.

In quiz section, the quiz is based on the learning knowledge by pulling content from SQLite and using Genymotion to adjust the final result.

\section{RESULT}

The end result of system is based on the actual testing in grade 3 students from primary school in Ratchaburi province. The group of 20 students are using this application along with class study and giving the test result and feedback as follows:

Administrator mode:

- Log-in to the system.

- Registering to the system.

- Access to E-learning contents \& downloadable contents.

- Some E-learning subject provide optional quiz.

- Search function.

- Forum for learner to share/discuss knowledge.

- File organization Add, Modify, Delete.

- Profile management.

- History organization (Review Content). 
User mode:

- Topic selective.

- Content Summary

- Quiz

- Flexible in browsing

- Simple UI

- Design from user requirements.

The test result is based on the given time allocation of teacher to the students where the two weeks allocation on everyday task. The average time per slot is 78 minutes. Also, the parents of each student are given task to share their child where the average time is spending 52 minutes in 5 assignment tasks across in these two weeks.

Table 1. Summation of Usage Time

\begin{tabular}{|l|c|c|}
\hline & Male & Female \\
\hline Average usage per week & 7 & 7.7 \\
\hline $\begin{array}{l}\text { Average Time per usage } \\
\text { at school (minutes) }\end{array}$ & 72 & 84 \\
\hline $\begin{array}{l}\text { Willing to continue to } \\
\text { use. }\end{array}$ & $85.71 \%$ & $87.5 \%$ \\
\hline $\begin{array}{l}\text { Average time per usage } \\
\text { at home (minutes) }\end{array}$ & 48 & 54 \\
\hline
\end{tabular}

Table 2. Feedback Result

\begin{tabular}{|l|c|c|}
\hline \multicolumn{1}{|c|}{ Feedback (out of 5) } & Average & SD \\
\hline Quality of content & 2.95 & 0.1 \\
\hline $\begin{array}{l}\text { To support the class } \\
\text { knowledge }\end{array}$ & 2.95 & 0.1 \\
\hline Quality of application & 2.93 & 0.15 \\
\hline $\begin{array}{l}\text { Effective to learning } \\
\text { process }\end{array}$ & 2.97 & 0.07 \\
\hline
\end{tabular}

\section{DISCUSSION}

As this system is created based on the actual user (grade 3 school students) requirement and reviewed by the same group student, our purpose is to gain more contribution of student. The objective is gaining more attention and support the in-class education.

As shown in Table 1, our objective is to evaluate the contribution of learner. As the learners does not intention to use the E-learning before this research. To motivate learners to contribute the new learning tools are shown in both male and female. The result also shows the continuous of the involvement for all study period in both school and home. This usage time includes both quiz and learning content based on 2017 Thai education curriculum. 
A large number of involvements also require network traffic and computer resource. With this need, in our research has a large scale of computer resource in research lab. However, in real case, the system requires implementation resource in the organization. Therefore, with limited resource and recent technology, cloud server is suggested for the proposed system.

The quality from feedback is shown as above average due to the design and requirement of their choices, however they suggest that the improvement on the next version of application would be expected.

Overall, the customized system shows the significant improved in main objective of E-learning system. This also provides the solution that new trend of users needs the information in their own need format and their own need. The alternative solution is served their task achieved in this area.

\section{CONCLUSiON}

E-learning is challenged in every organization to customize for appropriate for each organization. The difference in objective, members' background and knowledge leads to different expectation. The customization system is a solution with a high cost of out-of-the-box software.

This paper suggest the customized E-learning system based on Android framework. The specific learning group are based on grade 3 primary school in Ratchaburi province. The features of this system are content sharing, online quiz and feedback system to the responding teacher in school. The implementation of deployed system is based on user's requirement that tend to meet with expectation.

The trend of user involvement is improving the participation in most of area especially support Thai core curriculum in primary school.

\section{ACKNOWLEDGEMENTS}

We would like to thank Faculty of Engineering, Thammasat University, Thammasat University, Optical and Quantum Communication Research Lab and National Research Council of Thailand.

\section{REFERENCES}

[1] Cisco Systems, Cisco Systems IQ Atlas, Cisco, 2001.

[2] K. Fry, "E-learning markets and providers: some issues and prospects", Education + Training, Vol. 43 No. $4 / 5$ pp. 233-9, 2001.

[3] S.M. Furnell, P.D. Onions, U. Bleimann, U. Gojny, M. Knahl, H. F. Roder and P.W. Sanders, "A security framework for online distance learning and training", Internet Research: Electronic Networking Applications and Policy, Vol. 8 No. 3, pp. 236-42, 1998.

[4] S. Alexander, "E-learning developments and experiences", Education + Training, Vol. 43 No. 4/5 pp. 240-8, 2001.

[5] S.H. Garrison and D.J. Borgia, "Using an Internet based distance learning to teach introductory finance", Campus-Wide Information Systems, Vol. 16 No. 4, pp. 136-9, 1999.

[6] D. Lance, "Venture captial veiwpoints and E-learning futures", The Business of E-learning: Bringing Your Organizationin the Knowledge Economy, Univeristy of Technology Sydney, 2000.

[7] P. Henry, "E-learning Technology, Content and Services", Education + Training, Vol. 43 No. 4, pp. 249-55, 2001. 


\section{AUTHOR}

Piya Techateerawat is a lecturer of Computer Engineering at Thammasat University. He received his B.Eng. from University of New South Wales, Australia with Honors in 2004. He continued his PhD study at Royal Melbourne Institute of Technology University, Australia, where he obtained his $\mathrm{PhD}$ in Wireless Sensor Network Security. His current interests involve applications of Sensor Network, Security and Quantum Cryptography.

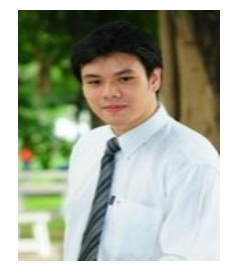

(C) 2020 By AIRCC Publishing Corporation. This article is published under the Creative Commons Attribution (CC BY) license. 